\title{
An electrophysiological follow up of patients with n-hexane polyneuropathy
}

\author{
Yang-Chyuan Chang
}

\begin{abstract}
Electroneurographic (ENeG) and evoked potential (EP) studies were regularly performed on 11 printing workers with n-hexane polyneuropathy after cessation of exposure. At the initial examination, the ENeG studies simulated a demyelinative process. Further slowing of nerve conduction velocity, or further decreasing of action potential amplitude, or both in the follow up ENeG study were found in about half the patients. The motor distal latency did not worsen. Nerve conduction returned to normal earlier in the sensory than in the motor nerves. After the patients had regained full motor capability, conduction velocities in motor nerves were still significantly slowed. These ENeG characteristics correlate with the pathological and pathophysiological changes in experimental hexacarbon neuropathies. The initial findings from the EP studies indicated a conduction abnormality in the central nervous system (CNS). Delayed worsening occurred in the amplitude of visual EPs in three patients. On serial follow up, the interpeak latency and interpeak amplitude of visual EPs improved little. Residual abnormalities were also found in the interpeak latency of auditory EPs in the brainstem and in the absolute latency of scalp somatosensory EPs from the peroneal nerve. Astroglial proliferation in the CNS probably impedes recovery of the abnormalities in EP.
\end{abstract}

Electroneurophysiological assessment is important in clinical neurotoxicology. Electroneurographic (ENeG) studies provide valuable information to allow a distinction between a demyelinating and an axonopathic process in a toxic polyneuropathy, and further investigation of the causative agent may become easy. Evoked potential (EP) studies can objectively evaluate the toxic effect of a specific agent

Department of Neurology, National Taiwan University Hospital, Taipei, Taiwan

Y-C Chang on the central nervous system (CNS). In patients with n-hexane polyneuropathy, a noticeable fall in nerve conduction velocities (NCV), profound amplitude reduction of compound muscle action potentials (CMAPs) and sensory action potentials (SAPs), and obvious prolongation of distal latencies (DLs) were characteristic ENeG findings. ${ }^{1-4}$ Prolongation of conduction times in the visual, auditory, and somatosensory pathways in the CNS has been shown by EP studies. ${ }^{5-7}$ Evolution of these electrophysiological abnormalities on recovery from n-hexane polyneuropathy, however, has never been systematically reported.

From December 1983 to February 1985, 28 printing workers in the Taipei area developed clinically overt n-hexane neuropathy as a result of occupational exposure. Epidemiological, ENeG, and EP findings in that outbreak have been reported. ${ }^{48}$ Eleven among these patients were regularly followed for a four year period at the Department of Neurology, National Taiwan University Hospital. Evolution of clinical manifestations after exposure had ceased has been published elsewhere. ${ }^{9}$ In the present paper $\mathrm{ENeG}$ and EP findings on recovery from n-hexane neuropathy are reported. Special attention is given to delayed worsening of the electrophysiological features.

Materials and methods

PATIENTS

Seventeen of the 28 patients in the Taipei outbreak of n-hexane neuropathy returned to south Taiwan and were lost to contact. The remaining 11 male patients were followed up monthly for the first two years, once every two months in the third year, and once every three months in the fourth year. They were not in contact with any organic solvents at work during this time. Their age ranged from 18 to 30 at the first examination.

Polyneuropathy was classified into grade 5, unable to stand without support or confined to a wheelchair; grade 4 , able to stand without support but unable to walk; grade 3, able to walk with support; grade 2, able to walk without support but unable to walk on heels for 10 steps; grade 1, able to walk freely on heels but 
unable to run; and grade 0 , able to run. At the first visit, grade 5 polyneuropathy was found in one, grade 4 in two, grade 3 in one, and grade 2 in the remaining seven patients. All of the patients returned to normal daily activities, including running, within one to four years. The sensory disturbance disappeared much earlier than the motor problem.

\section{ELECTRONEUROGRAPHIC STUDIES}

An ENeG study was carried out with an MS6 or a Mystro 20 electromyograph (MEDELEC) at the first visit and repeated when the polyneuropathic manifestations improved to a better clinical grade. After the patients recovered to grade 0 of neuropathy, it was necessary to repeatedly persuade them to receive a further neurophysiological examination. The final ENeG study was therefore conducted six to nine months after apparently complete recovery. With conventional techniques, motor nerve conduction studies were performed in the median (elbowwrist), the ulnar (elbow-wrist), the peroneal (kneeankle), and the tibial (knee-ankle) nerves. Sensory conduction velocities were also measured in the median (wrist-finger), the ulnar (wrist-finger), and the sural (midcalf-ankle) nerves. To obtain reliable distal latencies, the distance between recording site and distal stimulation point was kept as constant as possible. Electroneurographic findings from the right limbs were statistically compared with those from the normal controls used in a previous report. ${ }^{5}$

\section{EVOKED POTENTIAL STUDIES}

Multimodality evoked potentials were recorded with a Pathfinder II machine (Nicolet) when the patient received an ENeG follow up. Visual evoked potentials (pVEPs) to checkerboard pattern reversals were recorded at $\mathrm{Oz}-\mathrm{Cz}$ (10-20 system) with check size subtending $1^{\circ}, 30^{\prime}, 15^{\prime}$, and $7 \cdot 5^{\prime}$ of the visual angle at a reversal rate of $1 \cdot 88 / \mathrm{s}$. The number of trials was 256 and the analysis time was $250 \mathrm{~ms}$. The N1 (N75), P1 $(\mathrm{P} \overline{100})$, and $\mathrm{N} 2(\mathrm{~N} \overline{135})$ latencies of the pVEP from a visual angle of $30^{\prime}$ were measured. The amplitude measurements were referred to the N1-P1 and P1N2 interpeak amplitudes.

Brainstem auditory evoked potentials (BAEPs) to $0.1 \mathrm{~ms}$ clicks were recorded at $\mathrm{A} 2-\mathrm{Cz}$ or $\mathrm{A} 1-\mathrm{Cz}$ (ipsilateral to the side of click stimulation). The auditory stimulus in both condensation and rarefaction polarities was set at an intensity of $60 \mathrm{~dB}$ above threshold for each subject and at a rate of $11 \cdot 1 \mathrm{~Hz}$. The analysis time was $10 \mathrm{~ms}$ and 2048 trials were averaged. Out of the seven positive peaks, the absolute latencies of waves I, III, and V were measured.

Somatosensory evoked potentials (SEPs) to median nerve stimulation were recorded at the contralateral central region of the scalp $\left(\mathrm{C}^{\prime}\right.$ or $\left.\mathrm{C}^{\prime}\right)$, at the 7 th cervical spinous process, and at the ipsilateral Erb's point. Square wave pulse electric stimulation of $0.1 \mathrm{~ms}$ duration at a rate of $2.7 \mathrm{~Hz}$ was applied to the median nerve at the wrist and adjusted to the minimal current for eliciting visible thumb twitching. The analysis time was $50 \mathrm{~ms}$. The absolute latencies of the N1 (N20) component of scalp SEP, of the $\mathrm{N} \overline{13}$ peak of neck SEP, and of the negative peak of brachial nerve action potential (NAP) at the Erb's point were measured. Central somatosensory conduction time (CCT) was taken as the latency difference between scalp SEP latency (N1) and neck SEP latency $(\mathrm{N} \overline{13})$. Scalp SEPs at $\mathrm{Cz}^{\prime}$ to stimulation of the peroneal nerve at the ankle were also recorded with an analysis time of $200 \mathrm{~ms}$ and at a stimulation rate of $2 \cdot 1 \mathrm{~Hz}$. The absolute latency of $\mathrm{P} 1(\mathrm{P} \overline{\mathrm{40}})$ was selected for analysis.

Visual evoked potentials from the right eye, BAEP findings from the right ear, and SEP findings from the right limbs were used for statistical comparison with those from the normal controls used in a previous report. ${ }^{4}$

\section{EVOLUTION OF ELECTRODIAGNOSTIC ABNORMALITIES}

Evolution curves of $Z$ value of some important electrodiagnostic parameters were plotted on $X-Y$ diagrams with mean $Z$ value against different clinical grade on recovery. The $Z$ value of an electrodiagnostic parameter was calculated as:

$$
\begin{aligned}
& \mathrm{Z} \text { value }= \\
& \frac{\text { An obtained value }- \text { mean of controls }}{\text { Standard deviation }(\mathrm{SD}) \text { of controls }}
\end{aligned}
$$

\section{Results}

INITIAL AND FINAL ENeG FINDINGS (TABLES 1 AND 2)

Table 1 shows the motor and table 2 the sensory ENeG findings of the 11 patients at the initial and final examinations. The characteristic features at the first study, similar to those in the previous reports, were the noticeable fall of NCV, profound amplitude reduction of CMAP and SAP, and obvious prolongation of DL. Electroneurographic abnormalities were more severe in motor than in sensory conductions. The greatest abnormal findings were seen in the motor conduction of the peroneal nerve; the peroneal motor NCV ranged from 27.2 to $37.9 \mathrm{~m}$ per s, CMAP amplitude from 0.3 to $3.3 \mathrm{mV}$, and DL from 6.48 to $9 \cdot 12 \mathrm{~ms}$. In comparison with the normal controls, the motor NCVs at the final study were still significantly slower, whereas there was a tendency for higher MAP amplitudes from the median, the ulnar, and the tibial nerves. For sensory conduction in the final study, the patients had a faster mean sensory NCV and a lower mean SAP amplitude than the normal controls, but these differences did not reach statistical significance. 
Table 1 Motor neurographic findings in 11 patients with n-hexane polyneuropathy

\begin{tabular}{|c|c|c|c|c|}
\hline & $\begin{array}{l}\text { Initial } \\
\text { study } \\
(\text { mean }(S D)) \\
(n=11)\end{array}$ & $\begin{array}{l}\text { Final } \\
\text { study } \\
(\text { mean }(S D))^{\star} \\
(n=11)\end{array}$ & $\begin{array}{l}\text { Normal } \\
\text { controls } \\
(\text { mean }(S D)) \\
(n=72)\end{array}$ & $\begin{array}{l}\text { p Value } \\
\text { (final } \\
\text { study } \mathrm{v} \\
\text { controls) }\end{array}$ \\
\hline $\begin{array}{l}\text { Median nerve: } \\
\text { CMAP amplitude }(\mathrm{mV}) \dagger \\
\text { Distal latency }(\mathrm{ms}) \\
\text { NCV }(\mathrm{m} / \mathrm{s}) \ddagger\end{array}$ & $\begin{array}{c}4 \cdot 1(2 \cdot 1) \\
6 \cdot 08(0 \cdot 74) \\
42 \cdot 9(7 \cdot 1)\end{array}$ & $\begin{array}{c}10 \cdot 0(2 \cdot 1) \\
3 \cdot 87(0 \cdot 39) \\
57 \cdot 3(2 \cdot 5)\end{array}$ & $\begin{array}{c}8.9(3.0) \\
3.71(0.44) \\
61.9(4 \cdot 6)\end{array}$ & $\begin{array}{l}\text { NS\$ } \\
\text { NS } \\
<0.005\end{array}$ \\
\hline $\begin{array}{l}\text { Ulnar nerve: } \\
\text { CMAP amplitude (mV) } \\
\text { Distal latency (ms) } \\
\operatorname{NCV~}(\mathrm{m} / \mathrm{s})\end{array}$ & $\begin{array}{c}4 \cdot 2(1 \cdot 7) \\
5 \cdot 04(0 \cdot 78) \\
40 \cdot 8(4 \cdot 6)\end{array}$ & $\begin{array}{c}8 \cdot 5(1 \cdot 1) \\
3 \cdot 05(0 \cdot 24) \\
52 \cdot 8(4 \cdot 1)\end{array}$ & $\begin{array}{c}7.8(2 \cdot 2) \\
3.03(0.40) \\
55 \cdot 4(4 \cdot 0)\end{array}$ & $\begin{array}{l}\text { NS } \\
\text { NS } \\
<0.05\end{array}$ \\
\hline $\begin{array}{l}\text { Peroneal nerve: } \\
\text { CMAP amplitude (mV) } \\
\text { Distal latency }(\mathrm{ms}) \\
\mathrm{NCV}(\mathrm{m} / \mathrm{s})\end{array}$ & $\begin{array}{c}1.8(1.0) \\
8 \cdot 18(1.09) \\
31.9(3.3)\end{array}$ & $\begin{array}{c}5 \cdot 6(2.5) \\
4 \cdot 82(0 \cdot 89) \\
46 \cdot 1(4 \cdot 9)\end{array}$ & $\begin{array}{c}5.9(1.9) \\
4.71(1.03) \\
53 \cdot 1(4 \cdot 4)\end{array}$ & $\begin{array}{l}\text { NS } \\
\text { NS } \\
<0.0005\end{array}$ \\
\hline $\begin{array}{l}\text { Tibial nerve: } \\
\text { CMAP amplitude (mV) } \\
\text { Distal latency (ms) } \\
\text { NCV }(\mathrm{m} / \mathrm{s})\end{array}$ & $\begin{array}{c}4 \cdot 0(2 \cdot 4) \\
7 \cdot 59(1 \cdot 28) \\
34 \cdot 5(4 \cdot 3)\end{array}$ & $\begin{array}{c}10 \cdot 7(5 \cdot 7) \\
4 \cdot 51(0 \cdot 24) \\
46 \cdot 3(4 \cdot 8)\end{array}$ & $\begin{array}{c}10 \cdot 2(3 \cdot 7) \\
4.53(0 \cdot 81) \\
49 \cdot 6(3.9)\end{array}$ & $\begin{array}{l}\text { NS } \\
\text { NS } \\
<0.05\end{array}$ \\
\hline
\end{tabular}

^The final study was conducted six to nine months after apparently complete recovery.

†CMAP = Compound muscle action potential.

$\ddagger \mathrm{NCV}=$ Nerve conduction velocity.

$\S N S=$ Non-significant $(p>0.05)$.

\section{DELAYED WORSENING OF ENeG ABNORMALITIES}

In the second $\mathrm{ENeG}$ study, which was performed when the neuropathic manifestations improved to the next clinical grade (five to 10 months after the initial evaluation), a further reduction of MAP in one or more nerves occurred in six patients, mainly in the peroneal nerve. The peroneal nerve became unexcitable in one patient. Five patients had a further fall in motor NCV. No delayed worsening of motor DL occurred. At sensory ENeG follow up, a further decrease of SAP amplitude was seen in five patients, mainly in the sural nerve. Further falls in sensory NCV occurred in five patients. Electrodiagnostic worsening did not correlate with the clinical "coasting phenomenon" and also occurred even in those patients with a continuous improvement of neuropathic manifestations.

\section{EVOLUTION OF ENeG ABNORMALITIES}

Recovery of ENeG abnormalities was slow regardless of clinical severity or delayed electrodiagnostic worsening. Figure 1 shows evolution curves of the mean $Z$ value in the NCV, the $D L$, and the amplitude of CMAP or SAP. When the clinical recovery reached grade 2 , there was a more rapid improvement of these electrodiagnostic abnormalities. Residual abnormal findings were still seen, however, even after the patients regained their full motor capability.

INITIAL AND FINAL EP ABNORMALITIES (TABLES 3-5) Tables 3, 4, and 5 list the pVEP, SEP, and BAEP findings at the initial and final studies. Patterns of EP abnormalities at the first examination were the same as those previously reported-that is, decreased pVEP amplitude, delayed absolute

Table 2 Sensory neurographic findings in 11 patients with n-hexane polyneuropathy

\begin{tabular}{|c|c|c|c|c|}
\hline & $\begin{array}{l}\text { Initial } \\
\text { study } \\
(\text { mean }(S D))^{\star} \\
(n=11)\end{array}$ & $\begin{array}{l}\text { Final } \\
\text { study } \\
(\text { mean }(S D)) \\
(n=11)\end{array}$ & $\begin{array}{l}\text { Normal } \\
\text { controls } \\
(\text { mean }(S D)) \\
(n=72)\end{array}$ & $\begin{array}{l}\text { p Value } \\
\text { (final } \\
\text { study } \mathrm{v} \\
\text { controls) }\end{array}$ \\
\hline $\begin{array}{l}\text { Median nerve: } \\
\text { SAP amplitude }(\mu \mathrm{V}) \\
\text { Distal latency }(\mathrm{ms}) \\
\mathrm{NCV}(\mathrm{m} / \mathrm{s})\end{array}$ & $\begin{array}{l}16(8) \\
3.08(0 \cdot 33) \\
46.0(4 \cdot 7)\end{array}$ & $\begin{array}{l}35(6) \\
2 \cdot 36(0 \cdot 17) \\
59 \cdot 6(4 \cdot 2)\end{array}$ & $\begin{array}{l}41(18) \\
2 \cdot 49(0 \cdot 25) \\
57 \cdot 1(5 \cdot 9)\end{array}$ & $\begin{array}{l}\text { NS } \\
\text { NS } \\
\text { NS }\end{array}$ \\
\hline $\begin{array}{l}\text { Ulnar nerve: } \\
\text { SAP amplitude }(\mu \mathrm{V}) \\
\text { Distal latency }(\mathrm{ms}) \\
\mathrm{NCV}(\mathrm{m} / \mathrm{s})\end{array}$ & $\begin{array}{l}14(5) \\
2 \cdot 79(0 \cdot 25) \\
43 \cdot 4(3 \cdot 9)\end{array}$ & $\begin{array}{l}27(5) \\
2 \cdot 32(0 \cdot 31) \\
54 \cdot 6(3 \cdot 7)\end{array}$ & $\begin{array}{l}34(15) \\
2 \cdot 27(0 \cdot 25) \\
53 \cdot 4(5 \cdot 1)\end{array}$ & $\begin{array}{l}\text { NS } \\
\text { NS } \\
\text { NS }\end{array}$ \\
\hline $\begin{array}{l}\text { Sural nerve: } \\
\text { SAP amplitude }(\mu \mathrm{V}) \\
\text { Distal latency }(\mathrm{ms}) \\
\mathrm{NCV}(\mathrm{m} / \mathrm{s})\end{array}$ & $\begin{array}{l}11(4) \\
3.62(0.28) \\
42 \cdot 5(3 \cdot 7)\end{array}$ & $\begin{array}{l}18(3) \\
2 \cdot 94(0 \cdot 22) \\
51 \cdot 3(3 \cdot 8)\end{array}$ & $\begin{array}{l}20(9) \\
3 \cdot 06(0 \cdot 50) \\
50 \cdot 4(4 \cdot 2)\end{array}$ & $\begin{array}{l}\text { NS } \\
\text { NS } \\
\text { NS }\end{array}$ \\
\hline
\end{tabular}

*At the initial study, sensory action potential (SAP) could not be elicited at the median nerve in one, the ulnar nerve in one, and the sural nerve in five patients.

See table 1 footnotes for other explanations. 

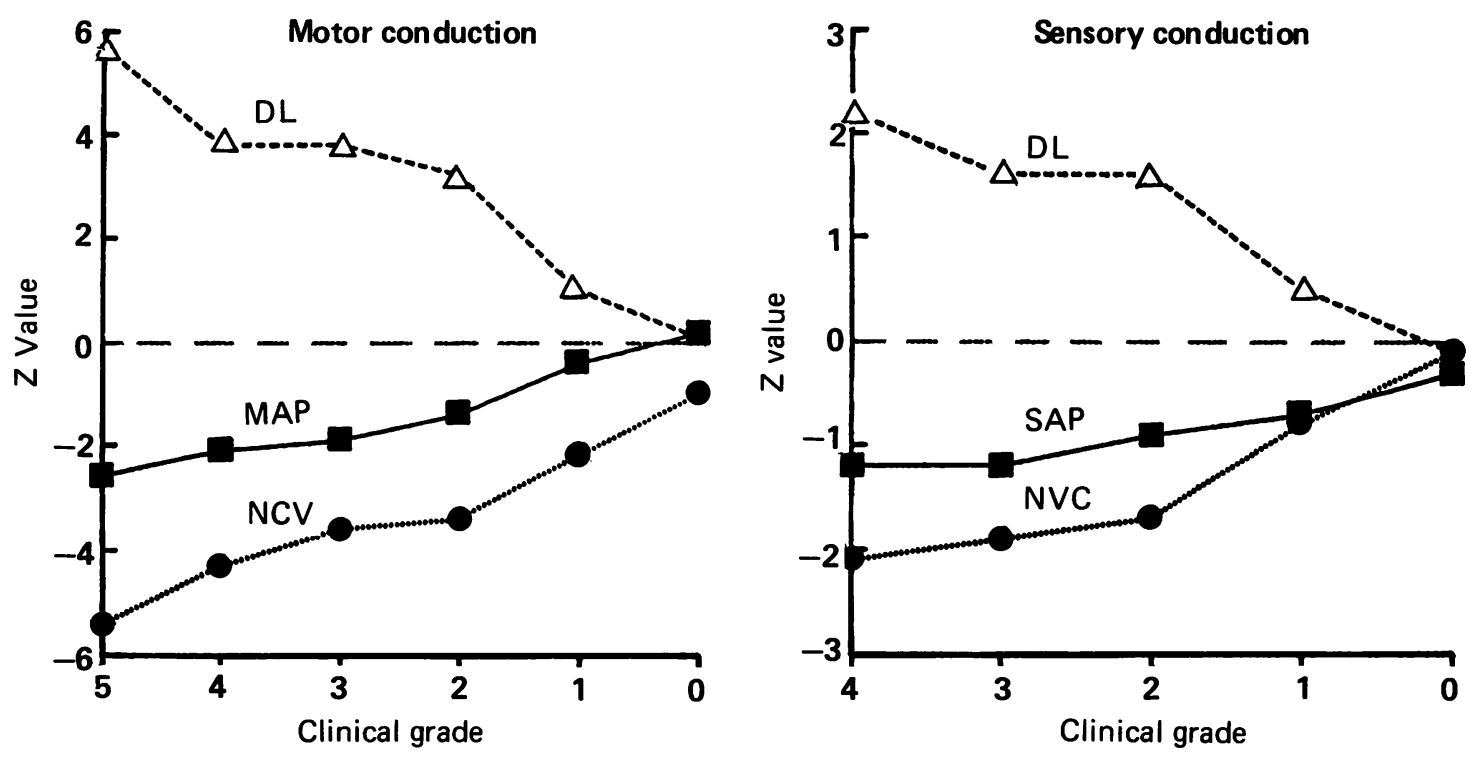

Figure 1 Evolution curves of mean $Z$ value in electroneurography in 11 patients with n-hexane polyneuropathy (NCV=nerve conduction velocity; $D L=$ distal latency; $M A P=$ muscle action potential; $S A P=$ sensory action potential; number of cases for each point = one for grade 5, three for grade 4, four for grade 3, and 11 for grades 2,1 , and 0 ).

latencies of pVEP and SEP, and prolonged auditory and somatosensory central conduction times. In comparison with normal controls, there were still significant prolongations of interpeak latency and reduction of interpeak amplitudes of pVEP at the final study. In the BAEP study, prolongation in the absolute latencies of wave III and $\mathrm{V}$ leading to prolongation of interpeak latencies was also statistically significant at the final examination. For the SEP findings, the only significant difference found was in the scalp SEP latency from the peroneal nerve.

\section{DELAYED WORSENING OF EP ABNORMALITIES}

Transient delayed worsening of EP findings only occurred in the interpeak amplitudes of pVEP. It was seen in three patients with grade 2 neuropathy. There was no concomitant complaint of visual worsening.

\section{EVOLUTION OF EP ABNORMALITIES}

Figure 2 shows evolution curves of the mean $Z$ value for some important EP parameters. For pVEPs, both the interpeak latency and interpeak amplitude improved little throughout the whole course. For SEPs from the median nerve, the central conduction time recovered earlier than the neck SEP latency. The interpeak latencies of BAEP improved rather slowly.

\section{Discussion}

A careful nerve conduction study offers clinicians useful clues to distinguish between a demyelinative and an axonal polyneuropathy. Obvious slowing of $\mathrm{NCV}$ and prolongation of DL are characteristic of demyelination, whereas axonal damage generally results in obvious amplitude loss of CMAP and SAP. Although the axon is the primary target in hexa-

Table 3 Findings of patterned visual evoked potential study in 11 patients with n-hexane polyneuropathy

\begin{tabular}{|c|c|c|c|c|}
\hline & $\begin{array}{l}\text { Initial } \\
\text { study } \\
(\text { mean }(S D)) \\
(n=11)\end{array}$ & $\begin{array}{l}\text { Final } \\
\text { study } \\
(\text { mean }(S D)) \\
(n=11)\end{array}$ & $\begin{array}{l}\text { Normal } \\
\text { controls } \\
(\text { mean }(S D)) \\
(n=44)\end{array}$ & $\begin{array}{l}\text { p Value } \\
\text { (final } \\
\text { study } \mathrm{v} \\
\text { controls) }\end{array}$ \\
\hline $\begin{array}{l}\text { N1 latency (ms) } \\
\text { P1 latency (ms) } \\
\text { N2 latency (ms) } \\
\text { N1-N2 interpeak latency (ms) } \\
\text { N1-P1 interpeak amplitude }(\mu \mathrm{V}) \\
\text { P1-N2 interpeak amplitude }(\mu \mathrm{V})\end{array}$ & $\begin{array}{l}75(5) \\
102(9) \\
141(14) \\
66(13) \\
4.99(2.48) \\
6.68(4.43)\end{array}$ & $\begin{array}{l}73(4) \\
96(6) \\
133(8) \\
61(10) \\
5 \cdot 13(2 \cdot 01) \\
7 \cdot 44(3 \cdot 10)\end{array}$ & $\begin{array}{l}72(4) \\
96(3) \\
127(7) \\
55(5) \\
8 \cdot 00(3 \cdot 49) \\
9 \cdot 36(2 \cdot 85)\end{array}$ & $\begin{array}{l}\text { NS } \\
\text { NS } \\
<0.05 \\
<0.01 \\
<0.05 \\
=0.05\end{array}$ \\
\hline
\end{tabular}

See table 1 footnotes for explanations. 
Table 4 Findings of somatosensory evoked potential study in 11 patients with $n$-hexane polyneuropathy

\begin{tabular}{|c|c|c|c|c|}
\hline & $\begin{array}{l}\text { Initial } \\
\text { study } \\
(\text { mean }(S D)) \\
(n=11)\end{array}$ & $\begin{array}{l}\text { Final } \\
\text { study } \\
(\text { mean }(S D)) \\
(n=11)\end{array}$ & $\begin{array}{l}\text { Normal } \\
\text { controls } \\
(\text { mean }(S D)) \\
(n=84)\end{array}$ & $\begin{array}{l}\text { p Value } \\
\text { (final } \\
\text { study } \mathrm{v} \\
\text { controls) }\end{array}$ \\
\hline 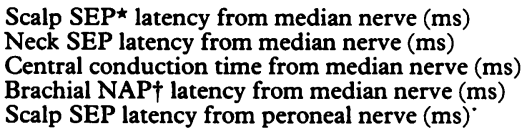 & $\begin{array}{r}20.68(0.97) \\
14.57(0.77) \\
6.14(0.61) \\
10.60(0.68) \\
44.88(3.00)\end{array}$ & $\begin{array}{r}18 \cdot 78(0 \cdot 77) \\
13.01(0 \cdot 54) \\
5 \cdot 77(0.41) \\
9 \cdot 32(0 \cdot 48) \\
41 \cdot 24(1 \cdot 74)\end{array}$ & $\begin{array}{r}18 \cdot 44(0.80) \\
12 \cdot 73(0.72) \\
5 \cdot 70(0.45) \\
9 \cdot 14(0.53) \\
39 \cdot 13(2 \cdot 45)\end{array}$ & $\begin{array}{l}\text { NS } \\
\text { NS } \\
\text { NS } \\
\text { NS } \\
<0 \cdot 01\end{array}$ \\
\hline
\end{tabular}

$\star$ SEP $=$ Somatosensory evoked potential.

†NAP = Nerve action potential.

See table 1 footnotes for other explanations.

carbon intoxication, pronounced slowing of NCVs simulating a demyelinative process has been reported in patients with hexacarbon neuropathy. ${ }^{1-4}$ The initial $\mathrm{ENeG}$ findings for the present patients with $\mathrm{n}$ hexane neuropathy (tables 1 and 2) also showed these features. Such an electrodiagnostic paradox is regarded as a result of secondary paranodal demyelination due to giant axonal swelling in hexacarbon neuropathy. ${ }^{1-3}$

The ENeG abnormalities in the present patients were more obvious in motor than in sensory conduction. This discrepancy was consistent with the fact that the motor deficit was more prominent than the sensory impairment. ${ }^{7}$ It also correlates well with findings in experimental rats exposed to 2,5-hexanedione $(2,5-\mathrm{HD})$ in which axonal transport was more vulnerable in motor than in sensory fibres. ${ }^{10}$

Delayed worsening of ENeG abnormalities after exposure to hexacarbon had ceased was first mentioned by Allen et al ${ }^{11}$ for workers in the outbreak of methyl n-butyl ketone (MnBK) polyneuropathy which occurred in Ohio, although they did not point out the ENeG parameters with delayed worsening. Cianchetti et al ${ }^{12}$ noted a progressive fall in motor NCV and reduction in MAP among shoe industry workers with n-hexane neuropathy even after removal from the work environment. Takahashi et al ${ }^{13}$ reported that a Japanese girl with $\mathrm{n}$-hexane polyneuropathy had a further fall of median motor NCV despite obvious improvement of DL, when her walking improved six months later. In the present group, ENeG parameters with delayed worsening included motor NCV, sensory NCV, CMAP amplitude, and SAP amplitude. Motor DL was not affected.

Recovery of ENeG abnormalities in our patients (tables 1 and 2 and fig 1) was earlier and more complete in sensory than in motor conduction and slowing of motor NCVs was still evident at the last follow up. Motor DL was no longer prolonged at the final examination. Exemption from delayed worsening and normalisation early in recovery in the motor DL probably have the same mechanism. Spencer and Schaumburg ${ }^{14}$ and Saida et al ${ }^{15}$ found that changes in experimental $\mathrm{MnBK}$ or 2,5-HD neuropathy appeared first in tibial nerve branches or the main sciatic trunk, and not in more distally placed nerves or in motor nerve terminals. If the most distal segments of motor nerve fibres are also less affected in n-hexane neuropathy in man, the motor DL, which reflects ENeG behaviour of distal motor fibres, would be spared from delayed worsening and would return to normal earlier.

At the final ENeG examination, higher CMAP amplitudes and faster sensory NCVs than those in normal controls were probably related to a younger age in the patient group than in the controls $(24.5 \mathrm{v}$ 27.0 years). Mean SAP amplitude at the final examination seemed lower than the normal controls, but the difference did not reach statistical significance.

Main EP abnormalities in both the hexacarbon exposed subjects ${ }^{5-7}$ and hexacarbon treated animals ${ }^{16}$ were prolongation of central conduction times and reduction of amplitudes. The findings in man, indicating neurotoxic effects on the CNS, fit well

Table 5 Findings of brainstem auditory evoked potential study in 11 patients with $n$-hexane polyneuropathy

\begin{tabular}{|c|c|c|c|c|}
\hline & $\begin{array}{l}\text { Initial } \\
\text { study } \\
(\text { mean }(S D)) \\
(n=11)\end{array}$ & $\begin{array}{l}\text { Final } \\
\text { study } \\
(\text { mean }(S D)) \\
(n=11)\end{array}$ & $\begin{array}{l}\text { Normal } \\
\text { controls } \\
(\text { mean }(S D)) \\
(n=50)\end{array}$ & $\begin{array}{l}\text { p Value } \\
\text { (final } \\
\text { study } \mathrm{v} \\
\text { controls) }\end{array}$ \\
\hline $\begin{array}{l}\text { Wave I latency (ms) } \\
\text { Wave III latency (ms) } \\
\text { Wave V latency (ms) } \\
\text { I-III interpeak latency (ms) } \\
\text { III-V interpeak latency (ms) } \\
\text { I-V interpeak latency (ms) }\end{array}$ & $\begin{array}{l}1.66(0 \cdot 15) \\
3.97(0.58) \\
5.99(0 \cdot 19) \\
2.31(0 \cdot 14) \\
2.02(0 \cdot 16) \\
4.33(0 \cdot 14)\end{array}$ & $\begin{array}{l}1.62(0.08) \\
3.89(0.31) \\
5.72(0.18) \\
2.18(0.12) \\
1.91(0.12) \\
4.09(0.17)\end{array}$ & $\begin{array}{l}1.62(0 \cdot 13) \\
3.70(0 \cdot 15) \\
5.55(0 \cdot 15) \\
2.08(0 \cdot 12) \\
1.85(0 \cdot 14) \\
3.94(0 \cdot 16)\end{array}$ & $\begin{array}{l}\text { NS } \\
<0.005 \\
<0.005 \\
<0.05 \\
\text { NS } \\
<0.01\end{array}$ \\
\hline
\end{tabular}

See table 1 footnotes for explanations. 

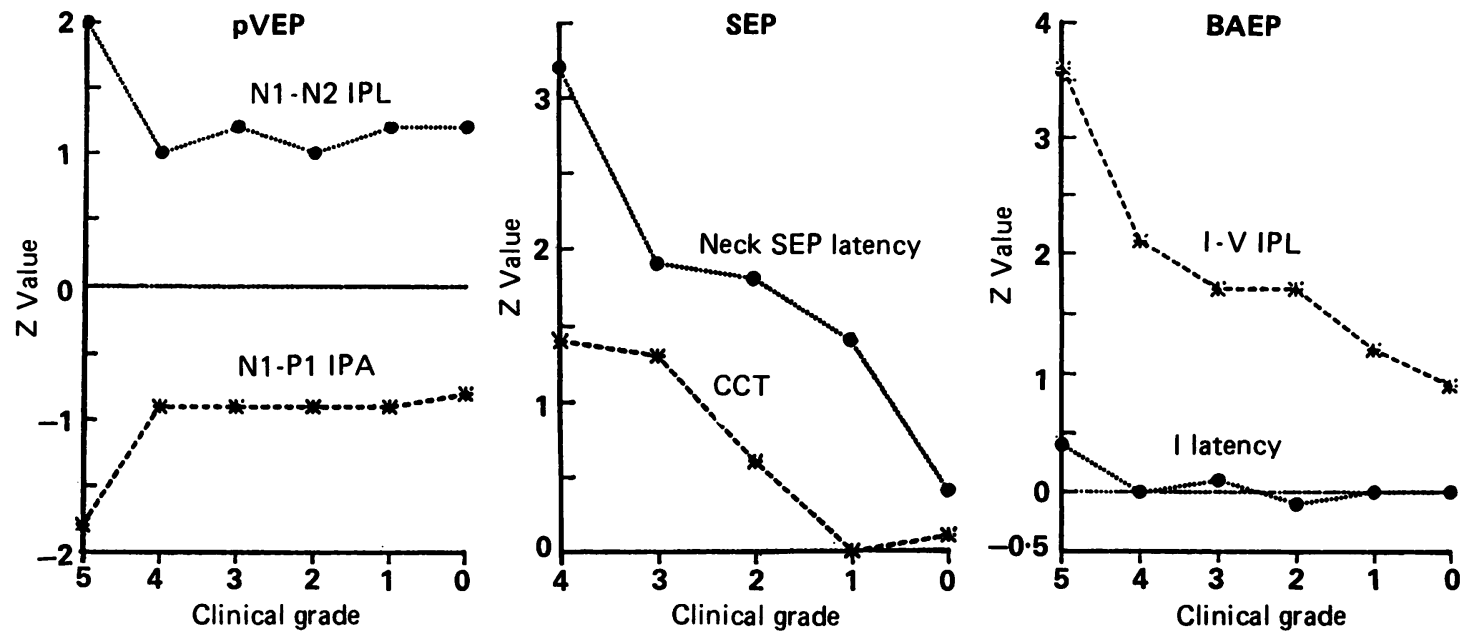

Figure 2 Evolution curves of mean $Z$ value in evoked potentials in 11 patients with $n$-hexane polyneuropathy (IPL=interpeak latency; IPA = interpeak amplitude; $C C T=$ central conduction time from median nerve; number of cases for each point =one for grade 5, three for grade 4, four for grade 3, and 11 for grades 2,1 , and 0 ).

with a pathological pattern of central peripheral distal axonopathy found in experimental animals. Recovery of EP abnormalities was much more unsatisfactory, however, than that of ENeG abnormalities. As shown in tables 3, 4, and 5, many EP findings in the final study were still significantly different from the normal controls. Astroglial proliferation triggered by hexane induced axonal degeneration impedes regeneration in the CNS; therefore poorer recovery of EP abnormality is understandable. Moreover, n-hexane maculopathy ${ }^{17}$ is also probably responsible for poor recovery of pVEP abnormalities.

Reasons for delayed worsening of electrophysiological abnormalities and clinical manifestations are not clear. After discovering more vulnerability in retrograde than anterograde axonal transport in rats treated with 2,5-HD, Braendgaard and Sidenius ${ }^{10}$ suggested that such a discrepancy could lead to structural changes (for example, axonal swellings) due to intraaxonal accumulation of membranous materials and cellular organelles. If the axonal transport recovers in a reverse order, the process of axonal change may continue for a period and then delayed worsening would ensue. This hypothesis needs careful confirmation, however.

Requests for reprints to: Dr Yang-Chyuan Chang, Department of Neurology, National Taiwan University Hospital, Taipei, Taiwan 10016, Taiwan.

1 Korobkin R, Asbury AK, Summer AJ, Nielsen SL. Gluesniffing neuropathy. Arch Neurol 1975;32:158-62.

2 Asbury AK, Johnson PC. Pathology of peripheral nerve. Philadelphia: W B Saunders, 1978:88-90.

3 Schaumburg HH, Spencer PS, Thomas PK. Disorders of peripheral nerves. Philadelphia: F A Davis, 1983:140-4.
4 Chang YC, Yip PK. n-Hexane-induced electroneurographic changes and early detection of $\mathbf{n}$-hexane intoxication. Journal of the Formosan Medical Association 1987;86:194-200.

5 Seppalainen AM, Raitta C, Huuskonen MS. n-Hexane-induced changes in visual evoked potentials and electroretinograms of industrial workers. Electroencephalogr Clin Neurophysiol 1979;47:492-8.

6 Mutti A, Ferri F, Lommi G, Lotta S, Lucertini S, Franchini I. $\mathrm{n}$-Hexane-induced changes in nerve conduction velocities and somatosensory evoked potentials. Int Arch Occup Environ Health 1982;51:45-54.

7 Chang YC. Neurotoxic effects of $n$-hexane on the human central nervous system: evoked potential abnormalities in n-hexane polyneuropathy. J Neurol Neurosurg Psychiatry 1987;50: 269-74.

8 Wang JD, Chang YC, Kao KP, Huang CC, Lin CC, Yeh WY. An outbreak of n-hexane induced polyneuropathy among press proofing workers in Taipei. Am J Ind Med 1986; 10:111-8.

9 Chang YC. Patients with n-hexane induced polyneuropathy: a clinical follow up. Br J Ind Med 1990;47:485-9.

10 Braendgaard $\mathrm{H}$, Sidenius $\mathrm{P}$. The retrograde fast component of axonal transport in motor and sensory nerves of the rat during administration of 2,5-HD hexanedione. Brain Res 1986; 378:1-7.

11 Allen M, Mendell JR, Billmaier DJ, Fontaine RE, O'Neill J. Toxic polyneuropathy due to methyl n-butyl ketone. Arch Neurol 1975;32:209-18.

12 Cianchetti C, Abbritti G, Perticoni G, Siracusa A, Curradi F. Toxic polyneuropathy of shoe-industry workers: a study of 122 cases. J Neurol Neurosurg Psychiatry 1976;39:1151-61.

13 Takahashi M, Takeuchi H, Kyo S, et al. n-Hexane polyneuropathy-a case report with a review of the literature. Med J Osaka Univ 1977;28:77-85.

14 Spencer PS, Schaumburg HH. Experimental neuropathy produced by 2,5-hexanedione-a major metabolite of the neurotoxic industrial solvent methyl n-butyl ketone. $J$ Neurol Neurosurg Psychiatry 1975;38:771-5.

15 Saida K, Mendell JR, Weiss HS. Peripheral nerve changes induced by methyl n-butyl ketone and potentiation by methyl ethyl ketone. J Neuropathol Exp Neurol 1976;35:207-25.

16 Rebert CS, Houghton PW, Hows RA, Pryor GT. Effects of hexane on the brainstem auditory response and caudal nerve action potential. Neurobehavioural Toxicology and Teratology 1982;4:79-85.

17 Raitta C, Seppalainen AM, Huuskonen NS. n-Hexane maculopathy in industrial workers. Albrecht von Graefes Archiv für Klinische und Experimentelle Ophthalmologie 1978;209:99-110.

Accepted 18 June 1990 